\title{
Spatial autocorrelation and impacts on criminology
}

\author{
Michael Townsley \\ School of Criminology and Criminal Justice, Griffith University, Australia \\ m.townsley@griffith.edu.au
}

The purpose of this essay is to map out the dissemination of Cliff and Ord's 1969 work in the field of criminology. I argue that despite criminology's widespread application of geography, the full implications of the article have yet to be realized. First, the major types of spatial studies in criminology are outlined, followed by a depiction of the context of criminological research at the time the article was published. Next the major changes to the field occurring after the publication of Cliff and Ord's paper, focusing on technology advances and theory, are set out. I finish by highlighting what I believe is a missed opportunity in criminological research that requires closer attention to spatial autocorrelation.

Criminology is the study of criminals, their actions (crimes), and society's response to those actions (the criminal justice system). The bulk of mainstream criminological research focuses on the first of these, and is interested in explaining criminality in terms of casual factors relating to onset, frequency, duration, severity and desistance (Piquero and Mazerolle 2000). The study of crimes has received relatively less attention, but this has changed over the last two decades ${ }^{1}$. Research in this last domain is concentrated in the sub-field of criminal justice.

\section{Types of studies of spatial influence in criminology}

Criminologists conceive and measure spatial influence in a number of different ways. One might pose that differences in crime counts or delinquency rates at the area level are due simply to area characteristics; that is, dependent and independent variables are aggregated to the area level, and each observation is considered statistically independent. In one of the very earliest spatial analyses in criminology, Guerry (1833) computed crime counts for French departments (counties) and found, rather surprisingly for the time, that neither poverty nor population density were associated with high crime

1 Due to the emergence of Problem-Oriented Policing (Goldstein 1979, 1990, Scott, Eck, Knutsson and Goldstein 2008), Situational Crime Prevention (Clarke 1997, 2008) and Crime Mapping (Eck and Weisburd 1995, Weisburd and McEwen 1997) and the literature on crime prevention generally (Sherman, Gottfredson, MacKenzie, Eck, Reuter and Bushway 1997) 
counts.

Considerable empirical evidence exists indicating that "place matters" (Tita and Greenbaum 2009), and that often areal level variables are found to poorly explain the dependent variable in question. This is not so much of a surprise because many of the predictors of crime and criminality (e.g., poverty, unemployment, ethnic heterogeneity) are spatially autocorrelated. A more realistic model would allow for the possibility that contiguous areas influence each other. Thus, the spatial structure of areas and their respective adjacency to other areas become the central points of interest. For instance, Morenoff, Sampson and Raudenbush (2001) model homicide rates at the neighborhood level using a spatially lagged dependent variable (i.e., homicide rates of contiguous neighborhoods) in addition to a range of intra-neighborhood characteristics. Consistent with the literature, they found neighborhood characteristics, by themselves, are insufficient to explain the distribution of homicide, and, moreover, demonstrate that the spatial effects of homicide are of greater magnitude than local characteristics. Other examples in this tradition include Baller, Anselin, Messner, Deane and Hawkins (2001), Bernasco and Luykx (2003), Brown (1982), Mencken and Barnett (1999), Roncek and Maier (1991), Smith, Frazee and Davison (2000), Weisburd, Bushway, Lum and Yang (2004).

Another body of spatial research in criminology focusses on individuals as the units of analysis, who themselves are located within spatially oriented structures such as gangs, schools or neighborhoods. Here, researchers attempt to partition, say, area-level differences from individual-level differences to explain whether simply residing in particular areas is enough to explain the distribution of victimization or criminality at the individual level. Findings by the Chicago School undoubtedly are the most well known body of research results from this tradition (Shaw and McKay 1969), and remain highly influential today. Shaw and McKay collected residential and demographic data about juvenile delinquents, and mapped (by hand) these data at the census tract level. These data allowed delinquency rates to be computed, which enabled them to be compared with leading areal indicators, giving rise to the seminal finding: delinquency rates for certain areas were stable over time, despite those areas hosting significant population turnover from a succession of different ethnic groups. Studies in this tradition are termed ecological studies of crime (Miethe and McDowall 1992, Sampson and Wooldredge 1987). A recent review of ecological studies by Sampson, Morenoff and Gannon-Rowley (2003) suggest that although contrasting methods and findings have emerged, four broad classes of neighborhood mechanisms can be identified: (i) social ties (the nature and number of relationships that exist in a neighborhood); (ii) collective efficacy (a composite of informal social control and social cohesion), (iii) institutional resources (the number and efficacy of facilities such as libraries, child care, neighborhood sport, or social organizations); and, (iv) routine activities (the location of 
schools, amount of commercial land use). An evidence base is emerging for these latter two mechanisms.

Ecological studies can be extended by allowing area adjacency to play a role. Thus, push-pull factors at the area level are included as independent variables. Examples in this tradition are Sampson, Morenoff and Earls (1999) and Bernasco and Nieuwbeerta (2005). Both of these studies are remarkable applications of well developed theory of the phenomena to be explained, criteria Elffers (2003) stipulated must be met to justify such complex models. For instance, Bernasco and Nieuwbeerta (2005) explain criminal location choice by integrating no less than three literatures: offender-based (journey to crime), target-based (attractiveness, ease of commission, area level risks), and mobility approaches (incorporating gravity models that measure the aggregate push-pull factors operating between areas).

Elffers (2003) cogently summarizes the criminological research about spatial effects using two attributes - units of analysis (place or person within a place), and scale of effect (within or between place). Combining these two features yields four possible combinations, as indicated in Table 1.

Table 1: Four types of spatial influence research problems scale of influence within area influence between area influence area correlational analysis adjacency (spatial autocorrelation, unit of gravity models) analysis individual ecological (multilevel within area models)

Note: Table adapted from Elffers (2003)

\section{Reasons spatial autocorrelation has had limited impact in criminology}

A strong ecological tradition exists in criminology, with adjacency studies featuring much less so. As an indication, the review by Sampson et al. (2003) syntheses no less than 
40 peer review studies of neighborhood effects published between 1996 and 2001 in the social and behavioral sciences. In this otherwise thorough and insightful review, inter-neighborhood effects are mentioned only in passing, and even this is to nominate spatial dependence between neighborhoods as a new direction in research of neighborhood processes ${ }^{2}$. I nominate three reasons for this state of affairs.

First, while the work of the Chicago School has been very influential, generating both theoretical and methodological advances, a number of criticisms (largely methodological and data-related; see Bottoms (1994) for a more detailed treatment) did much to diminish its popularity. With the computing and data processing capabilities in the mid$20^{\text {th }}$ century, ecological analyses were deemed fatal, and a general move away from this type of research occurred. For two decades, spatial approaches lay dormant in criminological research.

Second, the consequence of this shift in attention was an increased focus on individuals, and many sociologists embraced survey methodologies wholeheartedly. Longitudinal studies have come to dominate mainstream criminology, and the emergence of victimization surveys has further strengthened this methodology. Recently Raudenbush and Sampson (1999) call for the development of "ecometrics," an analogue to psychometrics dedicated to establishing reliable ecological measures by combining surveys, interviews and observation-based assessments.

Third, the tendency of spatial studies in criminology has been to move from large scale units of analysis (cities, regions, counties) to micro-units (census tracts, block faces, street corners). Weisburd, Bruinsma and Bernasco (2009) argue that this trend has not been accompanied by good theoretical explanations of micro-space (Eck (1997) and Weisburd and McEwen (1997) make similar points). Criminologists, like all social scientists, tend to construe data-driven research as "dust bowl empiricism" in the absence of strong, well-developed theoretical scaffolding.

To summarize, when Cliff and Ord published their original article, not only were spatial studies not popular in criminology, but criminology also had methodological and theoretical shortfalls it needed to overcome. Cliff and Ord's paper arguably came along at the worst time for criminology.

None of the preceding discussion suggests that spatial autocorrelation has been completely absent from criminological research in the intervening four decades. In the 1990s, a burgeoning research programme unfolded about violence in North America (examples include: Cohen and Tita 1999, Messner, Anselin, Baller, Hawkins, Deane and Tolnay 1999, Morenoff and Sampson 1997, Rosenfeld, Bray and Egley 1999, Smith et

2 To be clear the review does include studies that specifically deal with spatial autocorrelation and the authors did comment the lack of consistency in the way that area effects were operationalized or theoretically framed. Even so, the fact that the four major classes of neighborhood mechanisms they identify do not include adjacency underscores the dominance of the ecological tradition. 
al. 2000). Tita and Greenbaum (2009) provide a cogent summary of this research, but conclude about the ecological tradition that "though many plausible explanations have been offered, the empirical findings offer little in the way of supporting definitive statements on the exact nature of the processes that influence crime patterns across space" (p146).

Criminological researchers typically see spatial autocorrelation as a methodological problem to be explained away, controlled for, or its absence demonstrated (through the use of ESDA, spatial lag terms in models, or examining residuals). Gravity models have not featured extensively in this literature, and researchers have not been interested in explaining the push-pull factors of crime (the work of George Rengert as well as Paul and Patricia Brantingham are notable exceptions).

\section{Reasons to expect greater attention to be paid to spatial autocorrelation}

Independent of academic developments, the compounding effect of Moore's Law on computer processing has made computers much, much more powerful and affordable enough that most researchers have their own machine. The consequence of this development is that modern geographic information systems (GISs) are intuitive and powerful, and are well within the capability of non-programmers to master.

While earlier researchers were restricted to arbitrary administrative boundaries that had little or no connection to processes generating crime, modern GISs allow researchers to create highly flexible units of analysis. For example, McCord and Ratcliffe (2007) and Rengert, Ratcliffe and Chakravorty (2005) created their own units of analysis to demonstrate an elegant way to combine point level variables with area characteristics to explain the presence of drug markets. For their study region, within a GIS environment, buffer regions equal to the expected "spatial reach" of different crime facilitators (e.g., pawn shops, bars, cash checking stores, transport nodes) were created. Combining these buffer regions with census tract boundaries, a sort of "hyper-Venn diagram" was generated. The units of analysis are the set of distinct buffer zone-census tract intersections ${ }^{3}$. For these new units of analysis, the count of drug arrests (the dependent variable) is easy to compute. The independent variables comprise a set of dichotomous variables relating to the presence of each type of crime generator, the demographic data relating to the census tract and the area of an observation. A spatial lag term is included to detect any residual spatial autocorrelation. Thus, the generation of highly

3 In the simplest case, a square (the census tract) might contain two circles, $A$ and $B$, centered on a bar and a subway respectively. Assuming there is an intersection between $A$ and $B$, such a census tract would have four observations: (i) A without $B$, (ii) B without $A$, (iii) A and B, and (iv) not $A$ or $B$. 
customizable units of analysis is possible due to technical advances in computing power and programming capability, as well as to the routine storing of crime and demographic data in electronic information systems capable of interrogation, exporting and analysis.

The importance of this customization point is difficult to overstate. As units of analysis become smaller, the types of research questions being tackled by criminologists inevitably will migrate from the within area column to the between area column in Table 1. Even if the ecological tradition remains dominant, the tendency for units of analysis to shrink means that a corresponding increase exists in the importance of push/pull factors of distinct units. That is, the difference between where criminals live and where criminals offend becomes larger the smaller the units of analysis become. Adjacency will become a fundamental feature in any spatial analysis, independent of theory. This has not been the case in the past.

In terms of theory, since the publication of the seminal Cliff and Ord paper, three new spatial crime theories have emerged that have had a significant impact on researcher focus. Each of the triumvirate of theories-rational choice theory (Cornish and Clarke 2008,1986 ), routine activity theory (Cohen and Felson 1979), and crime pattern theory (Brantingham and Brantingham 2008)—attempts to explain how an immediate environment or situation determines the occurrence or distribution of crime, and collectively are known as environmental criminology. While these factors do operate at different levels of resolution, together they provide the theoretical underpinning to justify exploring micro-spatial explanations of crime (e.g., even high crime neighborhoods have a majority of places that do not host crime; concentrations of crime exist in low crime neighborhoods). The momentum of geographic criminology leading up to Cliff and Ord was transitioning from macro units of analysis to finer levels of resolution, yet at the time, a clearly articulated theory that provided an analytic frame for criminologists to operate did not exist. Environmental criminology, therefore, served as the theoretical "missing link" that permitted researchers to explore the dynamics of spatial effects at very fine levels of geographic resolution. For other examples of micro explanations of crime (or justification for its exploration), see Sherman (1995), and Sherman, Gartin and Buerger (1989).

A third factor suggesting that spatial autocorrelation will feature more prominently in the future is the rise of the methodology of social network analysis in criminology. This approach is centrally concerned with capturing how observations are connected to other observations, and whether the volume and strength of these connections are causally interesting. For instance, the risk of having a juvenile record may be influenced by personal characteristics, but the number of peers who have juvenile records is likely to have a non-trivial influence as well. While social network models can be aspatial, an obvious form of connection is proximity in space (see Malm (2006) for an example of the intersection of spatial and social network analysis). Even though the network approach might be seen as a rival to gravity models, explicitly acknowledging and 
exploiting the interdependence of observations when explaining a construct of interest makes network models useful both methodologically (as an additional means to measure and control spatial effects) and theoretically. For further discussion about the application of this perspective on crime research, see Papachristos (2006), and Tita and Greenbaum (2009).

\section{An as yet unrealised opportunity for criminology}

A wider appreciation of spatial autocorrelation in criminology has the potential to advance methodology and understanding in a number of areas. One will be outlined here, a means to precisely measure spatial displacement; but, nominating others is not difficult.

Spatial displacement, when crime prevention measures move crime from a high crime area to a nearby low crime area, is one of the major criticisms leveled at crime prevention techniques that utilise environmental criminology, yet very few attempts have been made to develop indicators of measurement (Bowers and Johnson 2003, Weisburd and Green 1995, Weisburd, Wyckoff, Ready, Eck, Hinkle and Gajewski 2006). Because the displacement argument suggests that offenders will seek nearby similar opportunities if their preferred criminal opportunity is blocked or removed, measures of spatial autocorrelation seem to offer a viable quantification for investigating the extent of displacement.

A reliable indicator for measuring the level of spatial displacement is required in the wake of implementing a crime prevention scheme. A putative means of achieving this goal would be to establish measures of point-level perturbations for different time units (how much does a spatial distribution of crime within a suburb change from month to month, say), most likely through local spatial autocorrelation statistics. By computing values for periods before and after scheme implementation, the extent of change following scheme implementation could be compared to a baseline. Two types of change are of interest: the magnitude of crime (did crime go up, down or stay the same?), and the spatial distribution of incidents of crime (is the change within the bounds of the baseline variation?). This method shares features with the weighted displacement quotient proposed by Bowers and Johnson (2003), but has the advantage of a time series type design. It even could be used prospectively to detect statistically significant changes in point pattern distributions as a type of early warning system, whereas the weighted displacement quotient is restricted to evaluation applications because it requires a control area as well as defined pre/post time periods. 


\section{Concluding comments}

To conclude, a range of factors in criminology have hindered the full implications of the 1969 Cliff and Ord essay from being realized until now, which might be viewed as a disappointment associated with research generated by their article. A strong ecological tradition exists in criminology, which is underpinned by the dominance of studying the causal factors of criminality. If the potential of Cliff and Ord's essay are to be realized, there needs to be a move away from seeing the presence of spatial autocorrelation as a methodological issue that needs to be explained away. Fortunately the discipline is well placed at the moment to do this. Explaining the distribution of crime rather than criminality naturally focuses more on push-pull factors and adjacency approaches and this is fostered by the emergence of micro-spatial theories of crime. 


\section{References}

Baller, R. D., L. Anselin, S. F. Messner, G. Deane and D. F. Hawkins (2001), Structural Covariates of U.S. County Homicide Rates: Incorporating Spatial Effects, Criminology, 39(3), 561-588, doi:10.1111/j.1745-9125.2001.tb00933.x.

Bernasco, W. and F. Luykx (2003), Effects of Attractiveness, Opportunity and Accessibility to Burglars on Residential Burglary Rates or Urban Neighborhoods, Criminology, 41(3), 981-1002, doi:10.1111/j.1745-9125.2003.tb01011.x.

Bernasco, W. and P. Nieuwbeerta (2005), How do residential burglars select target areas? A new approach to the analysis of criminal location choice, British Journal of Criminology, 45(3), 296-315.

Bottoms, A. E. (1994), Environmental Criminology, in The Oxford Handbook of Criminology, edited by M. Maguire, R. Morgan, and R. Reiner, Oxford Univeristy Press, Oxford.

Bowers, K. J. and S. D. Johnson (2003), Measuring the Geographical Displacement and Diffusion of Benefit Effects of Crime Prevention Activity, Journal of Quantitative Criminology, 19(3), 275-301, doi:10.1023/A:1024909009240.

Brantingham, P. J. and P. L. Brantingham (2008), Crime Pattern Theory, in Environmental Criminology and Crime Analysis, edited by R. Wortley and L. Mazerolle, pp. 78-93, Willan Publishing, Cullompton.

Brown, M. A. (1982), Modelling the Spatial Distribution of Suburban Crime, Economic Geography, 58(3), 247-261, doi:10.2307/143513.

Clarke, R. V. (1997), Situational Crime Prevention: Successful Case Studies, Albany 
NY.

Clarke, R. V. G. (2008), Situational Crime Prevention, in Environmental Criminology and Crime Analysis, edited by R. Wortley and L. Mazerolle, pp. 178-194, Willan Publishing, Cullompton.

Cohen, J. and G. E. Tita (1999), Spatial Diffusion in Homicide: An Exploratory Analysis, Journal of Quantitative Criminology, 15(4), 451-493.

Cohen, L. E. and M. Felson (1979), Social Change and Crime Rate Trends: A Routine Activity Approach, American Sociological Review, 44(4), 588-608.

Cornish, D. B. and R. V. Clarke (2008), The rational choice perspective, in Environmental Criminology and Crime Analysis, edited by R. Wortley and L. Mazerolle, pp. 21-47, Willan Publishing, Cullompton.

Cornish, D. B. and R. V. G. Clarke (1986), The Reasoning criminal: Rational choice perspectives on offending, Springer-Verlag, New York.

Eck, J. E. (1997), What do those dots mean? Mapping theories with data, in Crime mapping and crime prevention, vol. 8, edited by D. L. Weisburd and T. McEwen, pp. 377-406, Criminal Justice Press, Monsey, NY.

Eck, J. E. and D. L. Weisburd (1995), Crime Places in Crime Theory, in Crime and Place, edited by J. E. Eck and D. L. Wesiburd, pp. 1-33, Criminal Justice Press, Monsey, NY.

Elffers, H. (2003), Analysing neighbourhood influence in criminology, Statistica Neerlandica, 57(3), 347-367.

Goldstein, H. (1979), Improving policing: A problem-oriented approach, Crime and 
Delinquency, 25(2), 236-58.

Goldstein, H. (1990), Problem-oriented Policing, McGraw-Hill.

Guerry, M. (1833), Essai sur la statistque morale de la France, Crochard, Paris.

Malm, A. E. (2006), Marijuana Cultivation in British Columbia: Using spatial and social network analysis techniques to inform evidence-based policy and planning, $\mathrm{PhD}$, Simon Fraser University.

McCord, E. S. and J. H. Ratcliffe (2007), A Micro-Spatial Analysis of the Demographic and Criminogenic Environment of Drug Markets in Philadelphia, The Australian and New Zealand Journal of Criminology, 40(1), 43-63.

Mencken, F. C. and C. Barnett (1999), Murder, nonnegligent manslaughter, and spatial autocorrelation in mid-south counties, Journal of Quantitative Criminology, 15(4), 407-422.

Messner, S. F., L. Anselin, R. D. Baller, D. F. Hawkins, G. Deane and S. E. Tolnay (1999), The spatial patterning of county homicide rates: An application of exploratory spatial data analysis, Journal of Quantitative Criminology, 15(4), 423450.

Miethe, T. D. and D. McDowall (1992), Contextual effects in models of criminal victimization, Social Forces, 71, 741-759.

Morenoff, J. D. and R. J. Sampson (1997), Violent crime and the spatial dynamics of neighborhood transition: Chicago, 1970-1990, Social forces, 76, 31-64.

Morenoff, J. D., R. J. Sampson and S. W. Raudenbush (2001), Neighborhood Inequality, Collective Efficacy, and the Spatial Dynamic of Urban Violence, Criminology, 
39(3), 517-558.

Papachristos, A. V. (2006), Social Network Analysis and Gang Reserch: Theory and Methods, in Studying youth gangs, edited by J. F. Short and L. A. Hughes, pp. 99-144, Rowman Altamira.

Piquero, A. R. and P. Mazerolle (2000), Life-course criminology: Contemporary and classic readings, Wadsworth Thomson Learning.

Raudenbush, S. W. and R. J. Sampson (1999), Ecometrics: toward a science of assessing ecological settings, with application to the systematic social observation of neighborhoods, Sociological methodology, 1-41.

Rengert, G. F., J. Ratcliffe and S. Chakravorty (2005), Policing Illegal Drug Markets: Geographic Approaches to Crime Reduction, Criminal Justice Press, Monsey, NY.

Roncek, D. W. and P. A. Maier (1991), Bars, Blocks, and Crimes Revisited: Linking the Theory of Routine Activities to the Empiricism of Hot Spots, Criminology, 29(4), 725-753.

Rosenfeld, R., T. M. Bray and A. Egley (1999), Facilitating violence: A comparison of gang-motivated, gang-affiliated, and nongang youth homicides, Journal of Quantitative Criminology, 15(4), 495-516.

Sampson, R. J., J. D. Morenoff and F. Earls (1999), Beyond social capital: Spatial dynamics of collective efficacy for children, American Sociological Review, 633660 .

Sampson, R. J., J. D. Morenoff and T. Gannon-Rowley (2003), Assessing "Neighborhood Effects": Social Processes and New Directions in Research, Annual Review of Sociology, 28, 443-478. 
Sampson, R. J. and J. D. Wooldredge (1987), Linking the micro-and macro-level dimensions of lifestyle-routine activity and opportunity models of predatory victimization, Journal of Quantitative Criminology, 3(4), 371-393.

Scott, M. S., J. E. Eck, J. Knutsson and H. Goldstein (2008), Problem-oriented policing and environmental criminology, in Environmental Criminology and Crime Analysis, edited by Wortley, Richard and L. Mazerolle, pp. 221-246, Willan Publishing, Cullompton.

Shaw, C. R. and H. D. McKay (1969), Juvenile Delinquency and Urban Areas: A Study of Rates of Delinquency in Relation to Differential Characteristics of Local Communities in American Cities, University of Chicago Press.

Sherman, L. W., D. Gottfredson, D. MacKenzie, J. E. Eck, P. Reuter and S. Bushway (1997), Preventing Crime: What Works, what Doesn't, What's Promising, US Department of Justice-Office of Justice Programs-National Institute of Justice.

Sherman, L. W. (1995), Hot Spots of Crime and Criminal Careers of Places, in Crime and Place, vol. 4, edited by J. E. Eck and D. L. Weisburd, pp. 35-52, Criminal Justice Press, Monsey, NY.

Sherman, L. W., P. Gartin and M. Buerger (1989), Hot spots of predatory crime, Criminology, 27(1), 27-56.

Smith, W. R., S. G. Frazee and E. L. Davison (2000), Furthering the Integration of Routine Activity and Social Disorganization Theories: Small Units of Analysis and the Study of Street Robbery as a Diffusion Process, Criminology, 38(2), 489-524, doi:10.1111/j.1745-9125.2000.tb00897.x.

Tita, G. E. and R. T. Greenbaum (2009), Crimes, Neighborhoods and Units of Analysis: Putting Space in its Place, in Putting Crime in its Place: Units of Analysis in 
Geographic Criminology, edited by D. L. Weisburd, W. Bernasco, and G. J. N. Bruinsma, pp. 145-170, Springer, New York.

Weisburd, D. L., G. J. N. Bruinsma and W. Bernasco (2009), Units of Analysis in Geographic Criminology: Historical Developments, Critical Issues and Open Questions, in Putting Crime in its Place: Units of Analysis in Geographic Criminology, edited by D. L. Weisburd, W. Bernasco, and G. J. N. Bruinsma, pp. 5-33, Springer, New York.

Weisburd, D. L., S. Bushway, C. Lum and S. M. Yang (2004), Trajectories of Crime at Places: A Longitudinal Study of Street Segments in the City Seattle, Criminology, 42(2), 283-322.

Weisburd, D. L. and L. Green (1995), Measuring Immediate Spatial Displacement: Methodological Issues and Problems, in Crime and Place, vol. 4, edited by J. E. Eck and D. L. Weisburd, pp. 349-61, Criminal Justice Press, Monsey, NY.

Weisburd, D. L. and T. McEwen (1997), Introduction, in Crime mapping and crime prevention, vol. 8, edited by D. L. Weisburd and T. McEwen, pp. 1-23, Criminal Justice Press, Monsey, NY.

Weisburd, D. L., L. A. Wyckoff, J. Ready, J. E. Eck, J. C. Hinkle and F. Gajewski (2006), Does Crime Just Move Around the Corner? A Controlled Study of Spatial Displacement and Diffusion of Crime Control Benefits, Criminology, 44(3), 549592. 